\title{
ADAM17 targets MMP-2 and MMP-9 via EGFR-MEK-ERK pathway activation to promote prostate cancer cell invasion
}

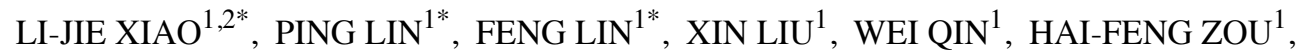 \\ LIANG GUO $^{1}$, WEI LIU ${ }^{1}$, SHU-JUAN WANG ${ }^{1}$ and XIAO-GUANG YU ${ }^{1}$ \\ ${ }^{1}$ Department of Biochemistry and Molecular Biology, College of Basic Medical Science, Harbin Medical University, \\ 194 Xuefu Road, Harbin 150081, Heilongjiang; ${ }^{2}$ College of Life Science and Technology, Heilongjiang Bayi \\ Agricultural University, 2 Xinyang Road, Daqing 163319, Heilongjiang, P.R. China
}

Received September 8, 2011; Accepted November 18, 2011

DOI: 10.3892/ijo.2011.1320

\begin{abstract}
ADAM17, also known as tumor necrosis factor- $\alpha$ converting enzyme (TACE), is involved in proteolytic ectodomain shedding of cell surface molecules and cytokines. Although aberrant expression of ADAM17 has been shown in various malignancies, the function of ADAM17 in prostate cancer has not been clarified. In the present study, we sought to elucidate whether ADAM17 contributes to prostate cancer cell invasion, as well as the mechanism involved in the process. The expression pattern of ADAM17 was investigated in human prostate cancer cells. The results showed that ADAM17 expression levels are correlated with the invasive ability of androgen-independent prostate cancer cell lines. Further, ADAM17 was overexpressed in cells showing high invasion characteristics, activation of the EGFR-MEK-ERK pathway, up-regulation of MMP-2, MMP-9, and an increased TGF- $\alpha$ release into the supernatant. However, AG1478, PD98059 and antibody against TGF- $\alpha$ deactivating the EGFR-MEK-ERK signaling pathway, abolished up-regulation of MMP-2, MMP-9 and prevented cell invasion. In addition, cells with knockdown of ADAM17 by siRNA exhibited low invasive ability, deactivated EGFR-MEK-ERK signaling pathway, reduced TGF- $\alpha$
\end{abstract}

Correspondence to: Professor Xiao-Guang Yu, Department of Biochemistry and Molecular Biology, College of Basic Medical Science, Harbin Medical University, 194 Xuefu Road, Harbin 150081, Heilongjiang, P.R. China

E-mail:yxg301@yahoo.com.cn

${ }^{*}$ Contributed equally

Abbreviations: ADAM17, a disintegrin and metalloprotease 17; ADAMs, a disintegrin and metalloproteinase; TACE, tumor necrosis factor- $\alpha$ converting enzyme; MMP-2 and MMP-9, matrix metalloproteinase- 2 and -9 ; TGF- $\alpha$, transforming growth factor- $\alpha$; EGFR, epidermal growth factor receptor; Akt, mitogenactivated protein kinase; ERK, extracellular signal-regulated protein kinase; ECM, extracellular matrix

Key words: a disintegrin and metalloprotease 17, transforming growth factor- $\alpha$, prostatic adenocarcinomas, matrix metalloproteinase- 2 and -9 released and down-regulation of MMP-2, MMP-9. However, these effects could be reversed by simultaneous addition of TGF- $\alpha$. These data demonstrated that ADAM17 contributes to androgen-independent prostate cancer cell invasion by shedding of EGFR ligand TGF- $\alpha$, which subsequently activates the EGFR-MEK-ERK signaling pathway, leading finally to overexpression of MMP-2 and MMP-9. This study suggests that the ADAM17 expression level may be a new predictive biomarker of invasion and metastasis of prostate cancer, and ADAM17 could provide a target for treating metastatic PCa.

\section{Introduction}

Prostate cancer $(\mathrm{PCa})$ is one of the most common malignancies among Western males with an occurrence of approximately 192,280 new cases and 27,360 deaths in the US, in 2009 (1). The growth and maintenance of cancerous cells in the early stages of prostate cancer is androgen-dependent and therapy often involves androgen deprivation (2). In the later stages therapeutic alternatives are not available, as the tumor progresses from androgen-dependence to -independence. The lack of effective therapies for advanced PCa is related to a large extent to poor understanding of the molecular mechanisms underlying the progression of disease toward invasion and metastasis (3). Therefore, the identification of new predictive biomarkers, especially those that are indicative of invasiveness of the disease, which could serve as targets for establishing effectiveness of therapeutic and chemopreventive interventions, will improve clinical management of PCa (4).

The ADAMs (a disintegrin and metalloproteinase) are members of the metzincin superfamily of $\mathrm{Zn}$-dependent matrix metalloproteinases. They are transmembrane and secreted proteins with important roles in diverse biological functions, such as fertilization, adhesion, migration, proteolysis and signaling $(5,6)$. Recently, specific ADAMs were implicated in a broad range of diseases, including Alzheimer's disease, asthma, diabetes, rheumatoid arthritis, atherosclerosis, kidney fibrosis, and cancer $(7,8)$. To date, 21 functional ADAMs have been described in humans and 40 in different organisms (9). Out of this long list of ADAMs, the best characterized ADAM family member is ADAM17. ADAM17, also known as tumor necrosis factor- $\alpha$ converting enzyme (TACE) was originally described 
as being responsible for the proteolytic cleavage of the soluble form of tumor necrosis factor- $\alpha(\mathrm{TNF}-\alpha)$, which is located on the cell surface $(10,11)$. However, subsequent studies showed that ADAM17 also sheds a variety of important cell surface molecules, including growth factors (12), adhesion molecules $(13,14)$ and chemokines $(15,16)$. Any of these play key roles in a variety of diseases, including cancer. Aberrant expression of ADAM17 has been shown in various malignancies (17-19).

However, reports on the expression and function of ADAM17 in prostate cancer are limited. ADAM17 mRNA expression was found in both androgen-dependent and androgen-independent prostate cancer cell lines (2). Subsequent study showed ADAM17 expression in non-cancerous (BPH) prostatic tissues was lower than that in tumor samples (20). Although the expression pattern for ADAM17 was determined in human prostatic adenocarcinomas, no functional assays were performed in these studies, where the expression has been investigated in a very limited way. Nevertheless, these studies raise the possibility of a functional role of ADAM17 in prostatic carcinomas. Therefore, the goal of this study was to investigate whether ADAM17 contributes to prostate cancer cell invasion and its mechanisms.

\section{Materials and methods}

Materials. Primary antibodies against Akt, p-Akt, and p-EGFR were purchased from Cell Signaling Technology; antibodies against ERK, p-ERK, MMP-2, MMP-9 and GAPDH were from Santa Cruz Biotechnology; ADAM17 antibody was obtained from Abcam and EGFR antibody from SAB. HRP-labeled antimouse or rabbit antibodies were from Santa Cruz Biotechnology. Geneticin and culture media were from Gibco (Grand Island, NY, USA) and Hyclone (Logan, UT), respectively. TGF- $\alpha$ and EGF were from R\&D Systems (Minneapolis, MN) and AG1478, LY294002, PD98059 were purchased from Cell Signaling Technology (Danvers, MA, USA). All the primers used in this research were synthesized by Shanghai Sangon Biotechnology Co., Ltd.

Cell culture. Human prostate cancer cell line DU145 and PC-3 were purchased from American Type Culture Collection, and PC-3M, PC-3M-1E8 and PC-3M-2B4 were obtained from the Peking University Health Science Center (Beijing, P.R. China). Cells were maintained in RPMI-1640 medium supplemented with $10 \%$ fetal bovine serum (FBS) (Gibco) and 1X penicillin/ streptomycin (Invitrogen, Carlsbad, CA, USA) at $37^{\circ} \mathrm{C}$ in a humidified atmosphere $\left(5 \% \mathrm{CO}_{2} / 95 \%\right.$ air $)$.

Stable transfection of ADAM17 cDNA. The cDNA encoding human ADAM17 was obtained from human placenta and the pcDNA3.0-vector were purchased from Invitrogen. pcDNA3.0ADAM17 was constructed by our laboratory. Stable transfection of pcDNA3.0-ADAM17 were done using Lipofectamine 2000 (Invitrogen) according to manufacturer's instructions. Fortyeight hours after transfection, $850 \mu \mathrm{g} / \mathrm{ml} \mathrm{G} 418$ was applied to select G418 resistant cells.

RNA interference. For siRNA treatments, two 25-nucleotide synthetic duplexes of ADAM17 siRNAs (ADAM17-siRNA1 and ADAM17-siRNA2) were prepared by Invitrogen. Sequences are as follows: ADAM17-siRNA1, 5'-AUGAGUUGUAACCAG GUCAGCUUCC-3'; ADAM17-siRNA2,5'-AUACAUGACAUA UUUCCCUCCCUGG-3'. DU145 cells grown to 40-60\% confluency were transfected with ADAM17 siRNA or a negative control siRNA using Lipofectamine 2000 (Invitrogen) according to manufacturer's protocol. The transfected cells were harvested at 48 or $72 \mathrm{~h}$ for mRNA isolation and protein extraction, respectively.

Transfections of PC-3-ADAM17 cells with MMP-2-siRNA or MMP-9-siRNA were performed as described above. Nucleotide synthetic duplexes of MMP-2-siRNA and MMP-9siRNA were obtained from Invitrogen. Sequences are as follows: MMP-2-siRNA, 5'-AGUAGAUCCAGUAUUCAUUC CCUGC-3'; MMP-9-siRNA,5'-AAUACAGCUGGUUCCCAA UCUCCGC-3'.

Semi-quantitative real-time PCR. Total RNA from control treated cells was extracted using TRIzol reagent (Invitrogen). Then, $2 \mu \mathrm{g}$ RNA was converted to cDNA with Superscript II reverse transcriptase (Invitrogen). The cDNA product was mixed with SYBR ${ }^{\circledR}$ Green PCR Master Mix (Applied Biosystems) and specific primers of ADAM17 or $\beta$-actin in the subsequent PCR using ABI7500 real-time PCR system (Applied Biosystems). Primers used in this study were as follows: $\beta$-actin, sense: 5'-TACCTCATGAAGATCCTCACC-3'; antisense: 5'-TTTCG TGGATGCCACAGGAC-3'; ADAM 17, sense:5'-AGCAACAG CATCCACCTAAT-3'; antisense: 5'-CAGGAGTGTCTGGAA TTGTC-3'. Annealing temperatures was $55^{\circ} \mathrm{C}$. Amplification cycles were 30 for ADAM17 and 23 for $\beta$-actin. Each reaction was done in triplicate to minimize experimental variation and transcript levels of $\beta$-actin were monitored as an internal control.

Western blot analysis. Cells treated with different compounds were harvested at indicated time, washed, and lysed in ice-cold lysis buffer (Beyotime Institute of Biotechnology, P.R. China) for $10 \mathrm{~min}$ on ice. The lysate was centrifuged at $12,000 \mathrm{~g}$ at $4^{\circ} \mathrm{C}$ for $5 \mathrm{~min}$. The protein concentration of extracts was determined with BCA reagent (Beyotime Institute of Biotechnology, P.R. China). Equal amounts of protein (40 $\mu \mathrm{g} /$ lane) were loaded, separated by $12 \%$ SDS-PAGE and transferred onto nitrocellulose membrane. After blocked with 5\% non-fat milk, the membranes were incubated with different primary antibody at $4^{\circ} \mathrm{C}$ overnight, and then HRP-labeled secondary antibodies. Immunoreactive bands were visualized using ECL Western blot detection reagents (Applygen Technologies Inc., Beijing, P.R. China). The expression levels of GAPDH were monitored as an internal control and the band intensities were normalized to that of GAPDH.

Matrigel invasion assay. Matrigel invasion assay were performed using Matrigel-coated transwell inserts containing polyacrbonate filters with $8 \mu \mathrm{m}$ pores (BD Biosciences, San Jose, CA) in accordance with manufacturer's instructions. Briefly, the inserts were pre-hydrated with serum-free RPMI1640 medium $(500 \mu \mathrm{l} /$ well $)$ for $2 \mathrm{~h}$ at $37^{\circ} \mathrm{C}$ in a humidified atmosphere $\left(5 \% \mathrm{CO}_{2} / 95 \%\right.$ air). Cells $\left(1 \times 10^{5}\right)$ in $200 \mu \mathrm{l}$ serumfree RPMI-1640 medium were plated onto the upper chambers, whereas $600 \mu \mathrm{l}$ complete medium was added to the lower wells. After $24 \mathrm{~h}$, cells on the upper surface of the filter removed by a cotton swab, and the invaded cells below the filter were fixed 
A
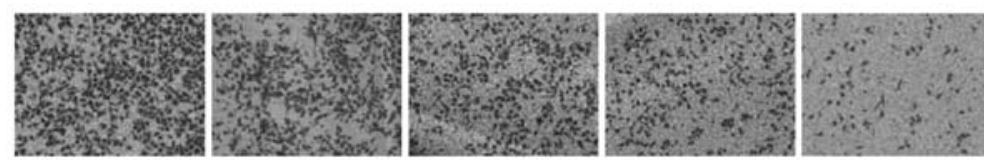

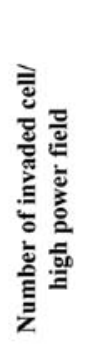

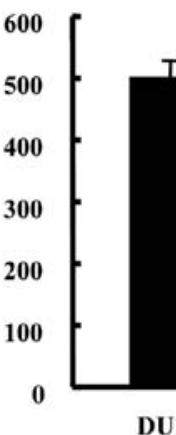

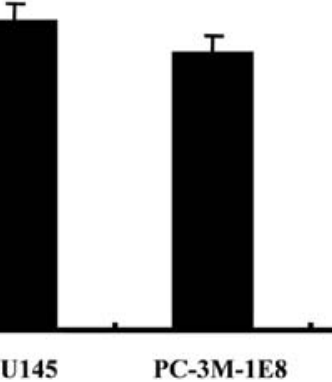

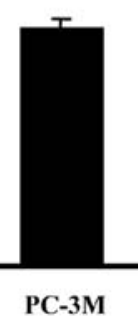

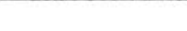

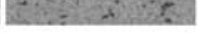

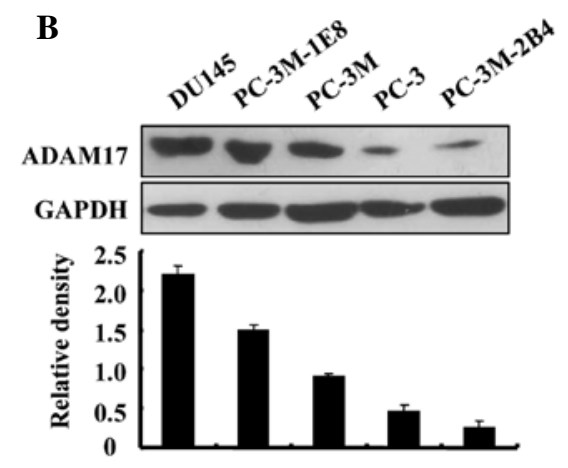

Figure 1. Expression of ADAM17 in human androgen-independent prostate cancer cell lines. (A), Matrigel invasion assays were performed to test the invasive ability of prostate cancer cell lines as described in Materials and methods. Representative fields of indicated cells that adhered to the bottom of the Matrigelcoated filters (upper panel) and quantitation of the same data (lower panel). (B), Representative image showing Western blot analysis on prostate cancer cell lines using anti-ADAM17 antibody (upper panel), and quantitation of the same data (lower panel).

in methanol for $20 \mathrm{~min}$, subsequently stained with $0.1 \%$ crystal violet for $30 \mathrm{~min}$. The numbers of invading cells were then counted in each of ten random fields for a given well under a light microscope (Olympus IX51, Japan) at a magnification of $\mathrm{x} 200$. Ten random fields were numerically averaged and counted for each assay. The invasion index for each treatment was calculated by dividing the number of invading cells by the number of cells that invaded under control group. Invasion index was expressed as percentages of control values, as previously described (21).

ELISA assay. The concentration of soluble TGF- $\alpha$ in supernatant and in total cellular extraction was determined by using commercial human TGF- $\alpha$ ELISA kit (Oncogene, Boston, MA) according to manufacturer's instruction.

Statistical analysis. Analyses were performed using the SAS system, version 9.1.3. The frequency of positive staining in different tissues was analyzed using $\chi^{2}$ test. Spearman rank correlation analysis was used to assess the correlation between gene expression levels and tumor differentiation status. Quantification of the bands from RT-PCR and Western blotting were determined by MetaView Image Analyzing System (Version 4.50; Universal Imaging Corp., Downingtown, PA) and each band was normalized by its corresponding control. Results were expressed as mean \pm SEM. $\mathrm{p}<0.05$ was considered as statistically significant.

\section{Results}

ADAM17 expression level correlates with cell invasiveness in androgen-independent prostate cancer cell lines. ADAM17 expression were investigated in five androgen-independent prostate cancer cell lines, DU145, PC-3, PC-3M, PC-3M-1E8 and $\mathrm{PC}-3 \mathrm{M}-2 \mathrm{~B} 4$, which were derived from different metastatic sites and have different metastatic potential in vivo. The DU145 cell line was originally isolated from brain of a patient with prostate cancer, while the PC-3 cell line was from a bone metastatic lesion. The PC-3M variant was isolated from a liver metastasis in nude mice produced by the intra-splenic injection of PC-3 cells. PC-3M-1E8 and PC-3M-2B4, which possess opposite metastatic potentials but similar genetic backgrounds, are subclones of PC-3M. In vitro DU145 was found to be the most highly invasive cell line in Matrigel invasion assay, while PC-3M-2B4 was found to have the least invasive ability (Fig. 1A). PC-3M-1E8 and PC-3M exhibited moderate invasive ability between that of DU145 and PC-3M-2B4. Low invasive ability was also detected in PC-3 cells, but was higher than that of PC-3M-2B4 (Fig. 1A).

ADAM17 protein levels were measured in the total lysates obtained from these five cell lines by Western blot analysis. The results showed endogenous levels of ADAM17 protein were expressed in all the five androgen-independent prostate cancer cell lines. As shown in Fig. 1B, the protein levels of ADAM17 were considerably higher in highly metastatic human prostate carcinoma cell line DU145 and PC-3M-1E8, compared to PC-3M-2B4, the poorly metastatic cell line. Low levels and moderate levels of ADAM17 were detected in PC-3 and PC-3M, respectively (Fig. 1B). The in vitro invasion assay showed ADAM17 expression level is correlated with invasive ability in androgen-independent prostate cancer cell lines.

Overexpression of ADAM17 increases invasiveness in prostate cancer PC-3 cells. To further verify the possibility that ADAM17 could contribute to prostate cancer cell invasiveness, stable transfection of the PC-3 cell line with a plasmid for overexpression of human ADAM17 was employed in this study to establish high levels of ADAM17 expression. As shown in Fig. 2A and B, stable ADAM17 transfectant, namely PC-3ADAM17, was detected to have increased levels of ADAM17 mRNA and protein compared with control vector transfection, named PC-3-Mock. Matrigel invasion assays were used to assess the invasive ability of PC-3-ADAM17 and PC-3-Mock to penetrate the extracellular matrix. The results showed that the invasiveness of PC-3-ADAM17 cells was $2.07 \pm 0.12$-fold higher than that of PC-3-Mock (Fig. 2C). 
A

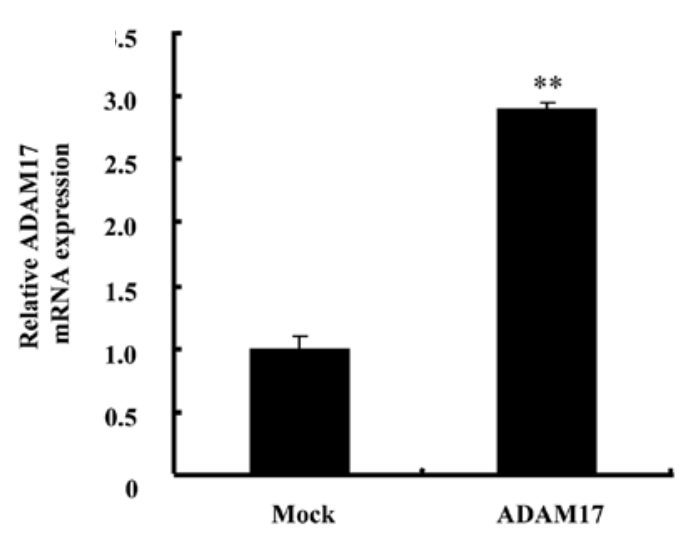

C

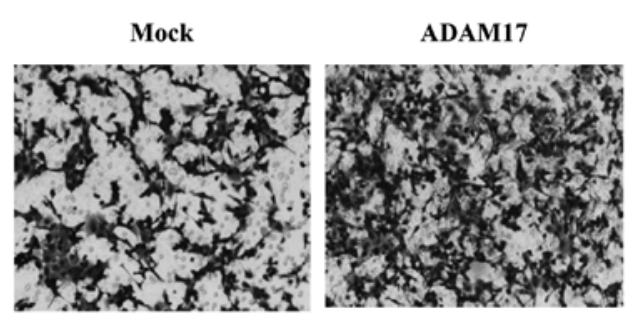

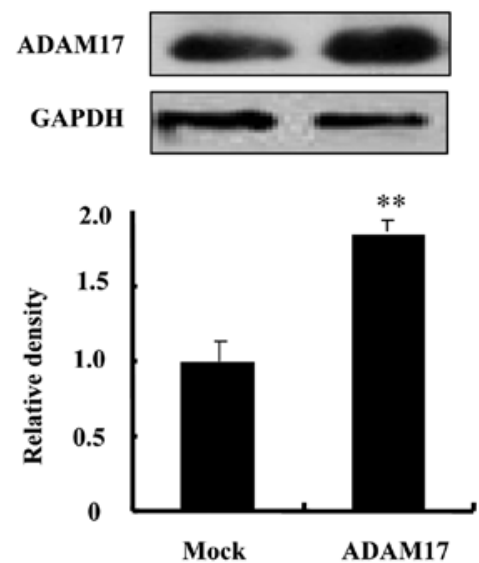

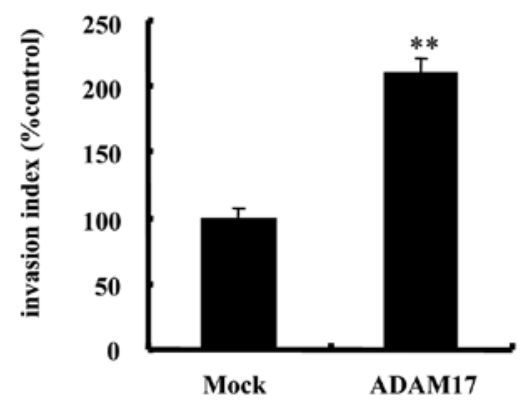

Figure 2. ADAM17 expression is correlated to PC-3 cell invasiveness in vitro. Analysis of ADAM17 expression in pcDNA3.0 vector (PC-3-Mock) and pcDNA3.0ADAM17 (PC-3-ADAM17) transfected PC-3 cells with (A), real-time PCR and (B), Western blotting. GAPDH was used as an internal control in real-time PCR and a loading control in Western blotting. (C), Invasion of PC-3-Mock and PC-3-ADAM17 cells through a Matrigel-coated basement membrane as indicated in Materials and methods. Data are means \pm SEM of three independent experiments. ${ }^{* *} \mathrm{p}<0.01$ vs control.

ADAM17 activates EGFR, Akt and ERK1/2 phosphorylation, and increases $M M P-2$ and MMP-9 expression in PC-3ADAM17 cells. To explore the possible cell signaling pathways involved in ADAM17-regulated cell invasion, we first examined the EGFR phosphorylation level in PC-3-ADAM17 cells. ADAM17 overexpression caused an $\sim 3$-fold increase in EGFR phosphorylation compared to PC-3-Mock, while total EGFR was not significantly affected by the level of ADAM17 (Fig. 3A). As EGFR activation can initiate a mitogenic cascade through ERK1/2 and Akt, we therefore investigate whether ADAM17 can activate Akt and ERK1/2. The levels of p-Akt and p-ERK were measured to evaluate the activation of PI3K-Akt and MAPK-ERK pathways after transfection of ADAM17. P-Akt and p-ERK expression showed significant increases in PC-3ADAM17 cells compared with the PC-3-Mock cells (Fig. 3A).

Extensive data show that metalloproteases (MMPs), in particular MMP-2 and MMP-9, play important roles in prostate cancer cell invasion and metastasis. Thereby, Western blot analysis was employed to determine MMP-2 and MMP-9 expression levels in PC-3-ADAM17 cells. The results showed overexpression of ADAM17 in PC-3-ADAM17 cells up-regulated MMP-2 and MMP-9 expression significantly. To determine the contribution of MMP-2 and/or MMP-9 to ADAM17-regulated cell invasion, two independent small interfering RNA sequences targeting MMP-2 and MMP-9 were used to silence MMP-2 and MMP-9 in PC-3-ADAM17 cells, respectively. Results presented in Fig. 3B and C demonstrated that the two siRNA inhibited MMP-2 and MMP-9 expression significantly at both RNA and protein levels, respectively, compared to CTL siRNA-transfected PC-3-ADAM17 cells. Moreover, the siRNA mediated knock-down of MMP-2 or MMP-9 of PC-3-ADAM17 cells resulted in decreased invasive ability to penetrate the extracellular matrix in vitro (Fig. 3D). These results revealed the involvement of MMP-2 and MMP-9 in ADAM17-mediated prostate cancer cells invasion in PC-3ADAM17 cells.

EGFR-MEK-ERK not EGFR-PI3K-Akt pathway is involved in ADAM17-induced MMP-2 and MMP-9 expression in $P C-3$ cells. As shown by previous studies MEK-ERK and PI3K-Akt pathways can up-regulate MMP-2 or MMP-9 expression in prostate cancer cells, we therefore examined whether these two pathways are all involved in ADAM17-mediated up-regulation of MMP-2, MMP-9 and cell invasion, or if one of them plays a more important role in this process. Increased phosphorylation of Akt induced by ADAM17 overexpression was prevented by PI3K-Akt inhibitor LY294002 in PC-3ADAM17 cells. However, the expression of Akt, MMP-2 and MMP-9 was not changed obviously by LY294002 treatment (Fig. 4A). Conversely, PD98059 prevented both ERK1/2 phosphorylation and MMP-2, MMP-9 expression in PC-3ADAM17 cells, indicating increased expression of MMP- 2 and MMP-9 by ADAM17 depends on ERK1/2 activation (Fig. 4B). Preincubation of PC-3-ADAM17 cells with EGFR inhibitor 

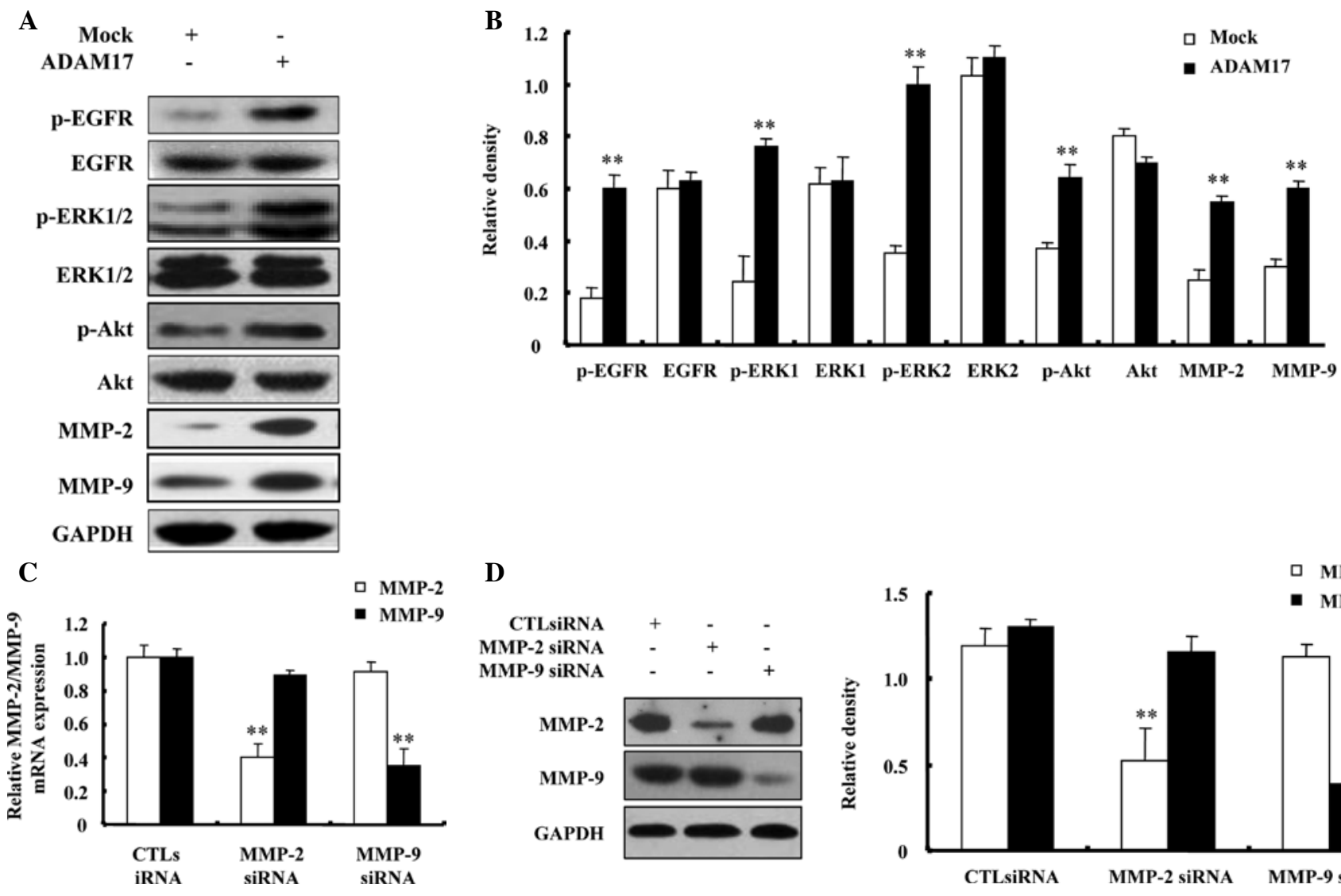

D
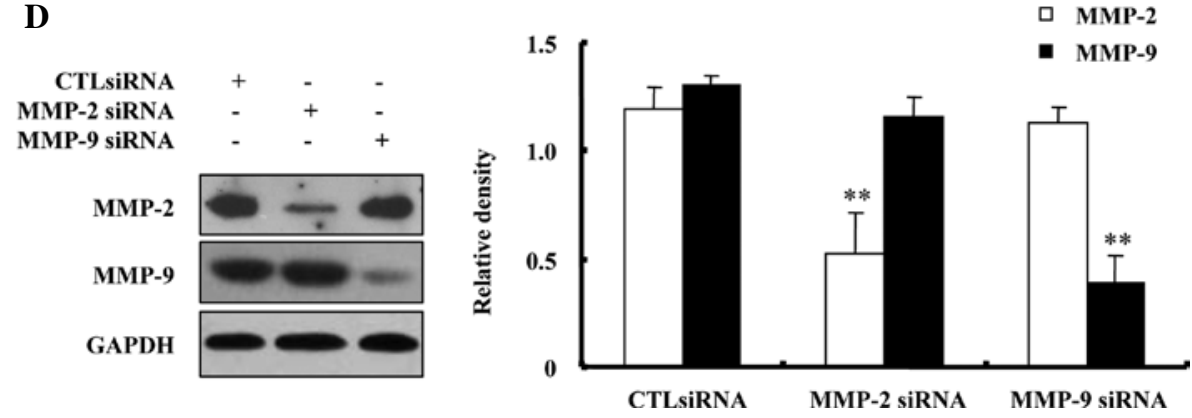

$\mathbf{E}$
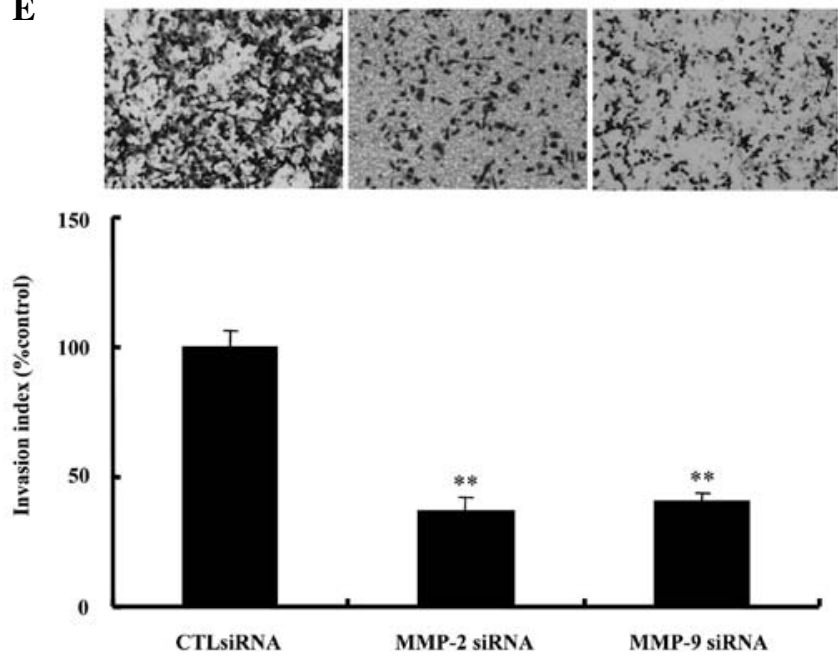

AG1478 significantly attenuated ADAM17-induced phosphorylation of EGFR and ERK, as well as the overexpression of MMP-2 and MMP-9 (Fig. 4C), indicating that ADAM17 regulates MMP-2 and MMP-9 expression through EGFRMEK-ERK, not EGFR-PI3K-Akt signaling pathway in PC-3-ADAM17 cells.

Invasion assays revealed, as expected, PD98059 and AG1478 prevented PC-3-ADAM17 cells from penetrating the extracellular matrix in vitro, while LY294002 had no effect on the invasiveness of PC-3-ADAM17 cells (Fig. 4D). Based on this observation, we concluded that ADAM17 promoted cell invasion by up-regulating MMP-2 and MMP-9 expression through EGFR-MEK-ERK pathway in PC-3-ADAM17 cells.
Figure 3. Effect of ADAM17 overexpression on activation of EGFR signaling pathway proteins and MMP-2, MMP-9 protein expression in PC-3 cells. (A), Overexpression of ADAM17 activated EGFR, Akt, ERK1/2 phosphorylation, and up-regulated MMP-2, MMP-9 protein levels in PC-3 cells. Total cell lysates from PC-3-Mock and PC-3-ADAM17 cells were subjected to immunoblot analysis with specific antibodies as indicated. The same blot were also stripped later and reprobed with antibody to GAPDH. Quantitative analysis of band density is shown in the right panel normalized to GAPDH. Each bar represents the means \pm SEM of three independent experiments. ${ }^{* *}<<0.01$ vs Mock. Knockdown of MMP-2 or MMP-9 mRNA and protein expression by siRNAs in PC-3-ADAM17 cells as shown by (B), real-time PCR and (C), Western blot analysis. (D), PC-3-ADAM17 cells transfected with MMP-2 siRNA or MMP-9 siRNA were subjected to Matrigel invasion assays. Each bar represents the means \pm SEM of three independent experiments. ${ }^{* *} p<0.01$ vs CTLsiRNA.
ADAM17 increases soluble $T G F-\alpha$ release which is a prerequisite for EGFR activation and cell invasion of PC-3-ADAM17 cells. To establish whether ADAM17 could cleave ectodomain of pro-TGF- $\alpha$ in PC-3-ADAM17 cells, we further performed TGF- $\alpha$ specific ELISA to determine the concentrations of soluble TGF- $\alpha$ released into the medium and the total TGF- $\alpha$ in cells. As shown in Fig. 5A, PC-3-ADAM17 cells had more TGF- $\alpha$ released to supernatant, compared to PC-3-Mock cells, while total TGF- $\alpha$ in these two cell lines were not affected by ADAM17 levels (Fig. 5B). Pretreatment of PC-3-ADAM17 cells with antibody to TGF- $\alpha$ decreased phosphorylated EGFR level, and inhibited cell invasion (Fig. 5B and C). These results indicated that ADAM17 increased the cell invasive ability through 
A
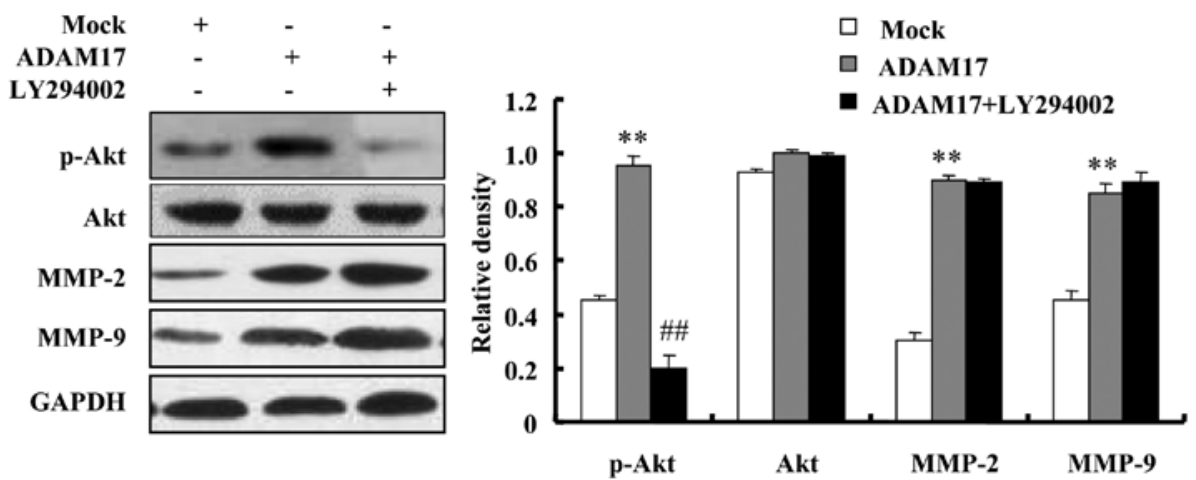

B
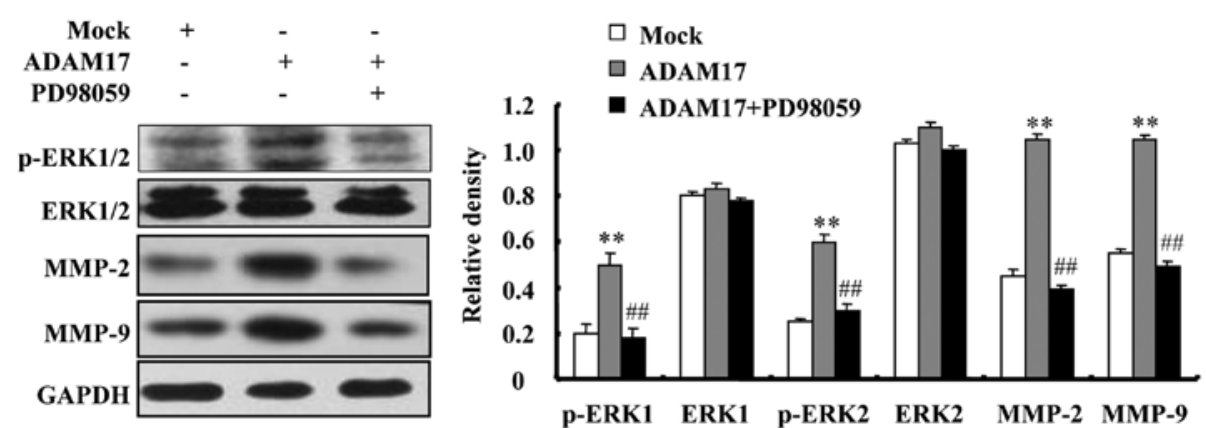

C
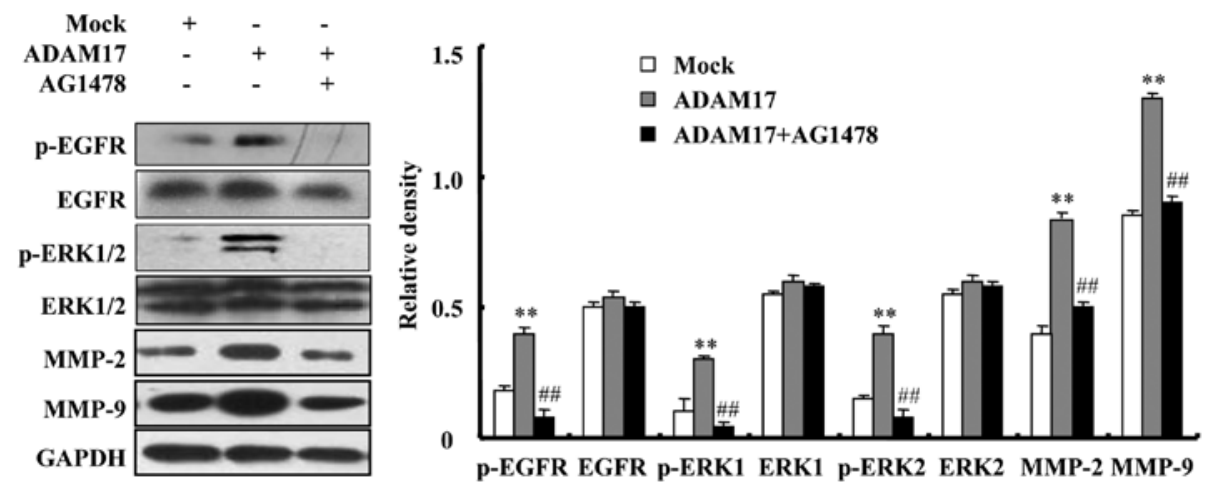

D

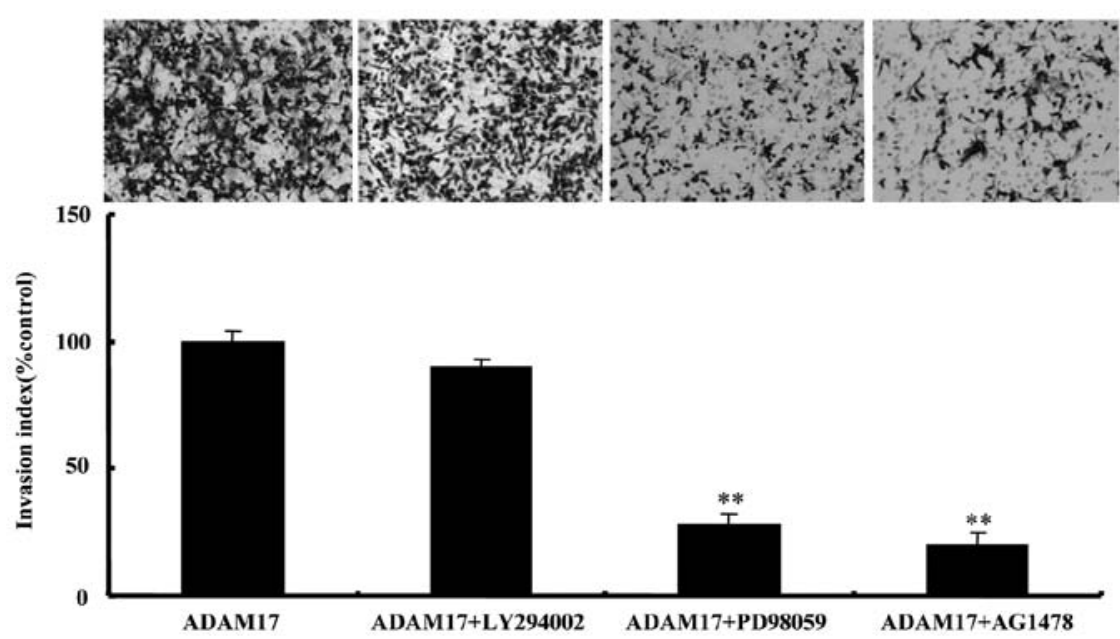

Figure 4. Involvement of EGFR-MEK-ERK pathway in ADAM17-induced MMP-2/MMP-9 expression and invasion in PC-3-ADAM17 cells. (A), Inhibition of AKT activity does not effect MMP-2 and MMP-9 expression. PC-3-ADAM17 cells were treated with or without $50 \mu$ M LY294002 for $24 \mathrm{~h}$ and were lysed. Cell lysates were subjected to immunoblotting with antibodies against p-AKT, AKT, MMP-2 and MMP-9. ${ }^{* *}$ p $<0.01$ vs Mock. ${ }^{\# \#}$ p $<0.01$ vs ADAM17. (B), MAPK inhibitor PD 98059 prevents p-ERK1/2 activation, down-regulates MMP-2 and MMP-9 expression. PC-3-ADAM17 cells were treated with or without $40 \mu$ M PD98059 for $24 \mathrm{~h}$ and then the cells were lysed. Cell lysates were subjected to immunoblotting with antibodies against p-ERK1/2, ERK1/2, MMP-2 and MMP-9. ${ }^{* *}$ p $<0.01$ vs Mock. "\# $\mathrm{p}<0.01$ vs ADAM17. (C), Inhibition of EGFR phosphorylation prevents ERK1/2 activity and up-regulation of MMP-2, MMP-9. PC-3-ADAM17 cells were treated with or without $1 \mu \mathrm{M}$ AG1478 for $24 \mathrm{~h}$ and were harvested. Then total cell lysates from these cells as well as from PC-3-Mock cells were subjected to immunoblotting with antibodies against p-EGFR, EGFR, p-ERK1/2, ERK1/2, MMP-2 and MMP-9. " $p<0.01$ vs Mock. ${ }^{* \#}$ p $<0.01$ vs ADAM17. (D), Effects of LY294002, PD98059 and AG1478 on invasiveness of PC-3-ADAM17 cell. PC-3-ADAM17 cells $\left(5 \times 10^{5}\right)$ were seeded into 60 mm-dish and allowed to attachment for $24 \mathrm{~h}$. Cells were pretreated with or without $50 \mu \mathrm{M} \mathrm{LY294002,} 40 \mu \mathrm{M}$ PD98059 or $1 \mu \mathrm{M}$ AG1478 for $1 \mathrm{~h}$. Then cells were washed by PBS and typsinized, followed by cell counting. Cells $\left(1 \times 10^{5}\right)$ in $200 \mu 1$ serum-free media containing LY294002, PD98059 or AG1478 were used in Matrigel invasion assays as described in Materials and methods. ${ }^{* *} \mathrm{p}<0.01$ vs PC-3-ADAM17. 
A
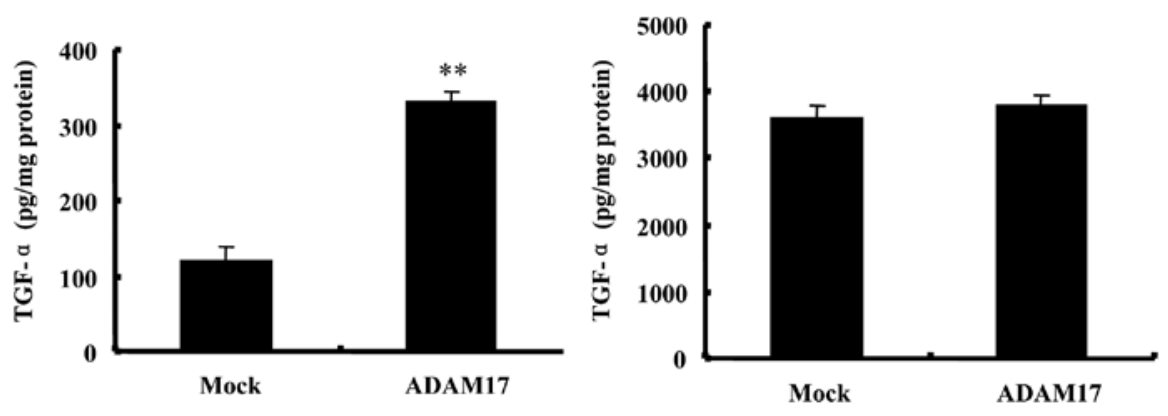

B
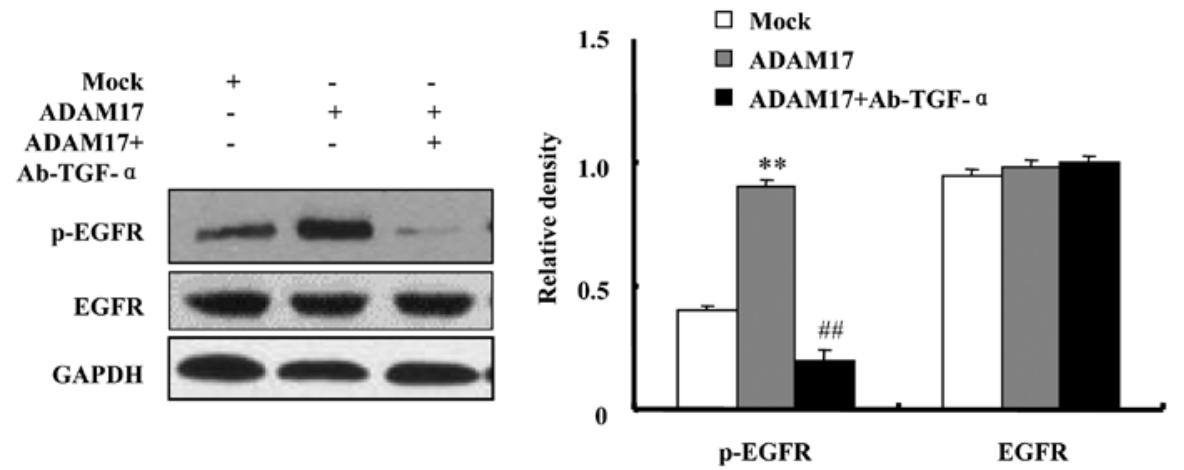

C

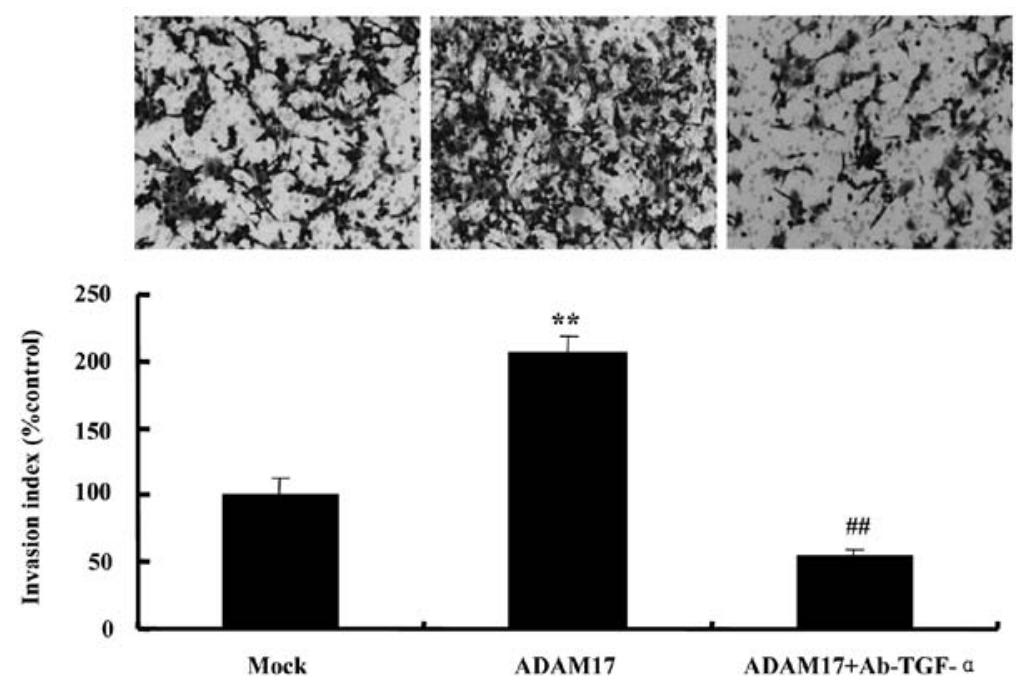

Figure 5. Release of soluble TGF- $\alpha$ is a prerequisite for ADAM17-mediated cell invasion in PC-3-ADAM17 cells. (A), ADAM17 increased soluble TGF- $\alpha$ releasing to the supernatant but had no effect on total TGF- $\alpha$. PC-3-ADAM17 cells $\left(5 \times 10^{5}\right)$ were seeded into $60 \mathrm{~mm}$-dish and allowed to attach for $24 \mathrm{~h}$, and were cultured in fresh media for another $24 \mathrm{~h}$. Then the media were collected and the cells were harvested. The concentration of soluble TGF- $\alpha$ in supernatant (left panel) and the total TGF- $\alpha$ in cellular extraction (right panel) of PC-3-ADAM17 cells were determined by a ELISA kit. " p $<0.01$ vs PC-3-Mock. (B), Ab-TGF- $\alpha$ prevented EGFR phosphorylation in PC-3-ADAM17 cells. PC-3-ADAM17 cells were pretreated with or without Ab-TGF- $\alpha$ for $1 \mathrm{~h}$, and were cultured in media containing $4 \mu \mathrm{g} / \mathrm{ml} \mathrm{Ab-TGF-} \alpha$ or not for another $24 \mathrm{~h}$. Then total cell lysates from these cells as well as from PC-3-Mock cells were subjected to immunoblotting with antibodies against p-EGFR, EGFR and GAPDH. ${ }^{* *}$ p $<0.01$ vs PC-3-Mock. ${ }^{\# \#}$ p $<0.01$ vs PC-3-ADAM17. (C), Ab-TGF- $\alpha$ inhibited PC-3-ADAM17 cell invasion. PC-3-ADAM17 cells $\left(5 \times 10^{5}\right)$ were pretreated with or without $4 \mu \mathrm{g} / \mathrm{ml}$ antibody against TGF- $\alpha$ for $1 \mathrm{~h}$, then cells were washed by PBS and typsinized, followed by cell counting. Cells $\left(1 \times 10^{5}\right)$ in $200 \mu \mathrm{l}$ serum-free media containing $4 \mu \mathrm{g} / \mathrm{ml}$ Ab-TGF- $\alpha$ were used in Matrigel invasion assays as described in Materials and methods. ${ }^{* *}$ p $<0.01$ vs PC-3-Mock. ${ }^{\# \#}$ p $<0.01$ vs PC-3-ADAM17.

mediating soluble TGF- $\alpha$ release, which subsequently activates EGFR signal pathway in PC-3-ADAM17 cells.

Knockdown of ADAM17 inhibited DU145 cell invasion by deactivating the signal pathways involved in the process. Since stable PC-3-ADAM17 overexpressing cells exhibited increased invasiveness, to further verify the contribution of ADAM17 to prostate cancer cells invasion, we investigated the effect of down-regulating ADAM17 in DU145 cells, which shows relatively high ADAM17 expression (Fig. 6D). Results of Fig. 6A showed that ADAM17 expression was significantly down-regulated at both RNA and protein levels in ADAM17siRNA-transfected DU145 cells. Soluble TGF- $\alpha$ released to supernatant was decreased while no apparent change of total TGF- $\alpha$ levels was observed in DU145 cells after ADAM17siRNAs transfection (Fig. 6B). Furthermore, knockdown of ADAM17 markedly blocked activation of EGFR, ERK1/2 and Akt, inhibited MMP-2 and MMP-9 expression 
A

B
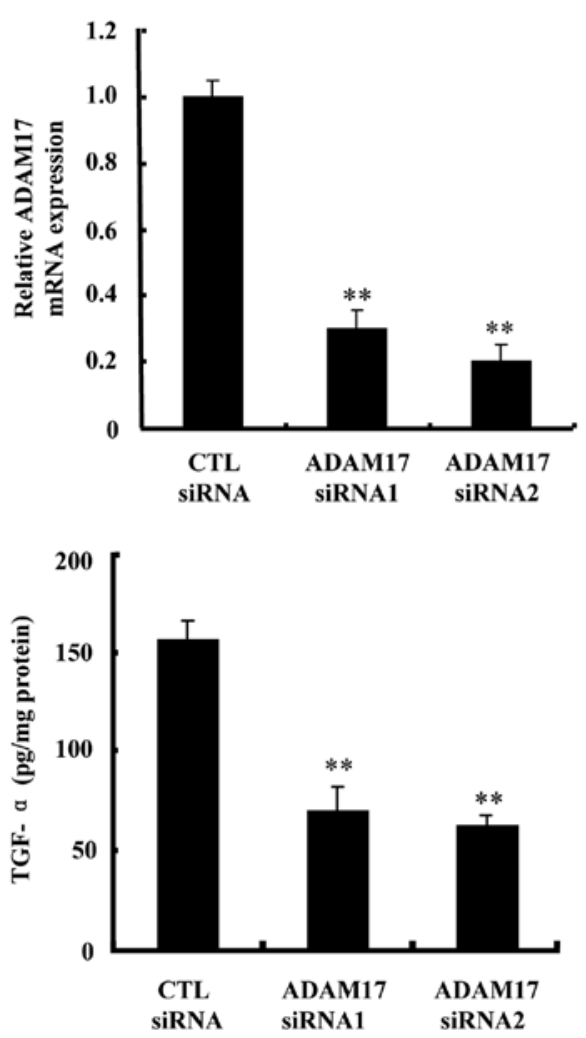

D

C

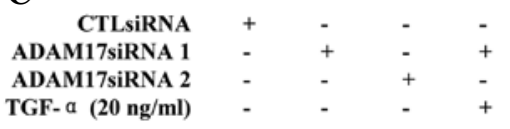

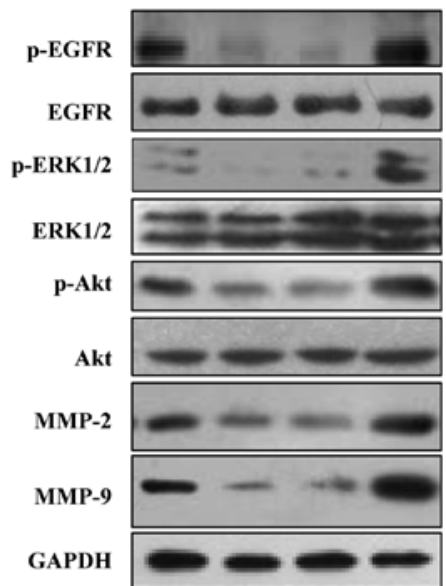

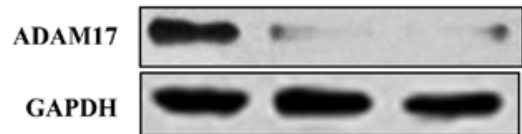

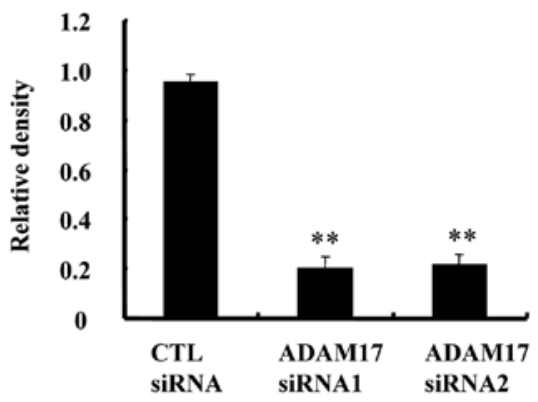

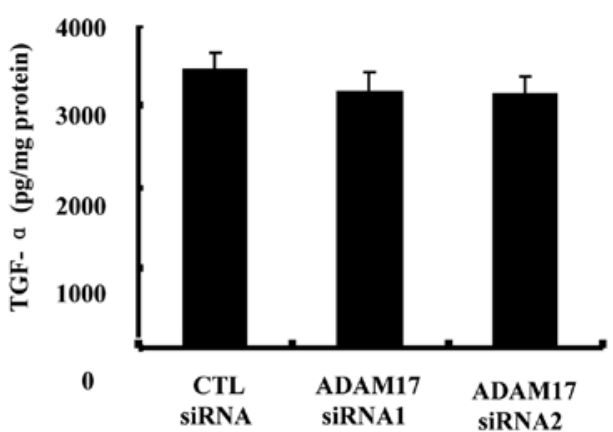

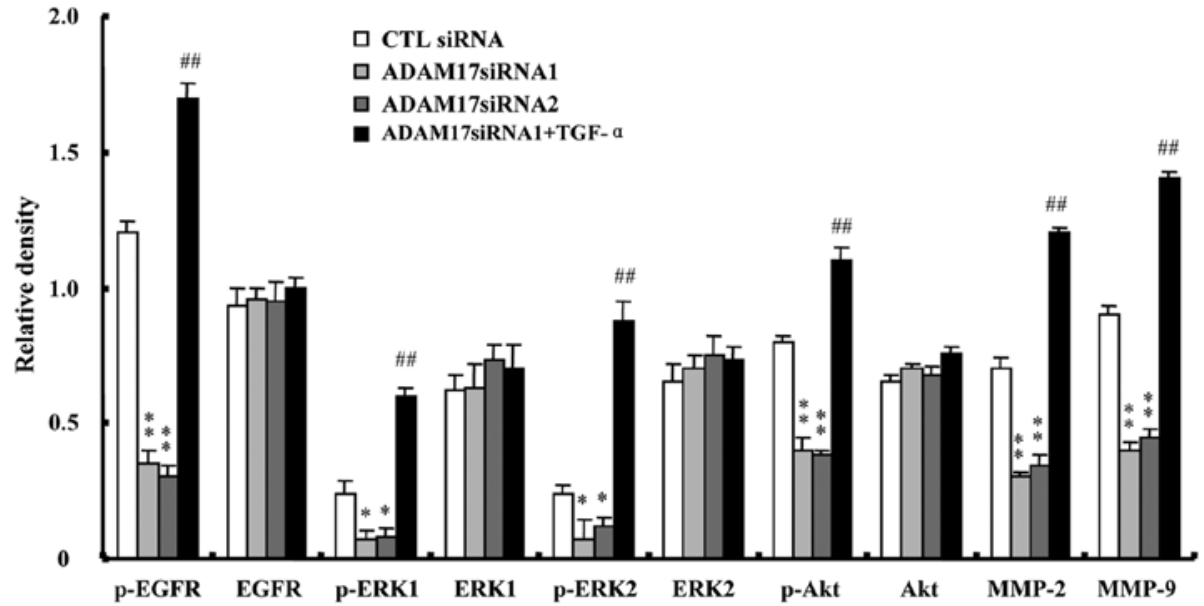

Figure 6. Knockdown of ADAM17 inhibited DU145 cell invasion. (A), Analysis of ADAM17 expression in ADAM17 siRNA-transfected DU145 cells with realtime PCR (left panel) and Western blotting (right panel). GAPDH was used as an internal control in real-time PCR and a loading control in Western blotting. (B), DU145 cells transfected with ADAM17 siRNAs or CTL siRNA for $72 \mathrm{~h}$ were cultured in fresh media for another $24 \mathrm{~h}$. Then the media were collected and the cells were harvested. The concentration of soluble TGF- $\alpha$ in supernatant (left panel) and the total TGF- $\alpha$ in cellular extraction (right panel) were determined by ELISA. ${ }^{* *}$ p $<0.01$ vs CTL siRNA. (C), Knockdown of ADAM17 deactivated EGFR, AKT, ERK1/2 phosphorylation, and down-regulated MMP-2, MMP-9 protein levels in DU145 cells, which could be reversed by exogenous soluble TGF- $\alpha$. DU145 cells transfected with ADAM17 siRNAs or CTL siRNA for $72 \mathrm{~h}$ were cultured in fresh media for 1 or $24 \mathrm{~h}$ with or without $20 \mathrm{ng} / \mathrm{ml}$ soluble TGF- $\alpha$. Then the cells were harvested and cell lysates were subjected to immunoblot analysis with specific antibodies as indicated. The same blots were stripped later and reprobed with antibody to GAPDH. (D), Quantitative analysis of band density normalized to GAPDH as to the result of $(C)$. Each bar represents the means \pm SEM of three independent experiments. ${ }^{* *}$ p $<0.01$ vs CTL siRNA. ${ }^{* \# p}<<0.01$ vs ADAM17siRNA1. (E), Knockdown of ADAM17 decreased cell invasive ability, which could be reversed by simultaneous addition of TGF- $\alpha$. DU145 cells were transfected by ADAM17 siRNAs or CTL siRNA for $72 \mathrm{~h}$. Then cells were washed by PBS and typsinized, followed by cell counting. Cells $\left(1 \times 10^{5}\right)$ in $200 \mu 1$ serum-free media with or without $20 \mathrm{ng} / \mathrm{ml}$ soluble TGF- $\alpha$ were employed in Matrigel invasion assays as described in Materials and methods. ${ }^{* * *} \mathrm{p}<0.01 \mathrm{vs}$ CTL siRNA. ${ }^{\# \#}$ p $<0.01$ vs ADAM17siRNA1.

and decreased cell invasive ability in DU145 cells, compared with CTL siRNA-transfected cells (Fig. 6C-E). However, exogenous soluble TGF- $\alpha(20 \mathrm{ng} / \mathrm{ml})$ restored the activation of EGFR, Akt and ERK signal pathways, up-regulation of MMP-2, MMP-9 and the invasiveness in ADAM17siRNAtransfected DU145 cells. Taken together with rest of the 
$\mathbf{E}$
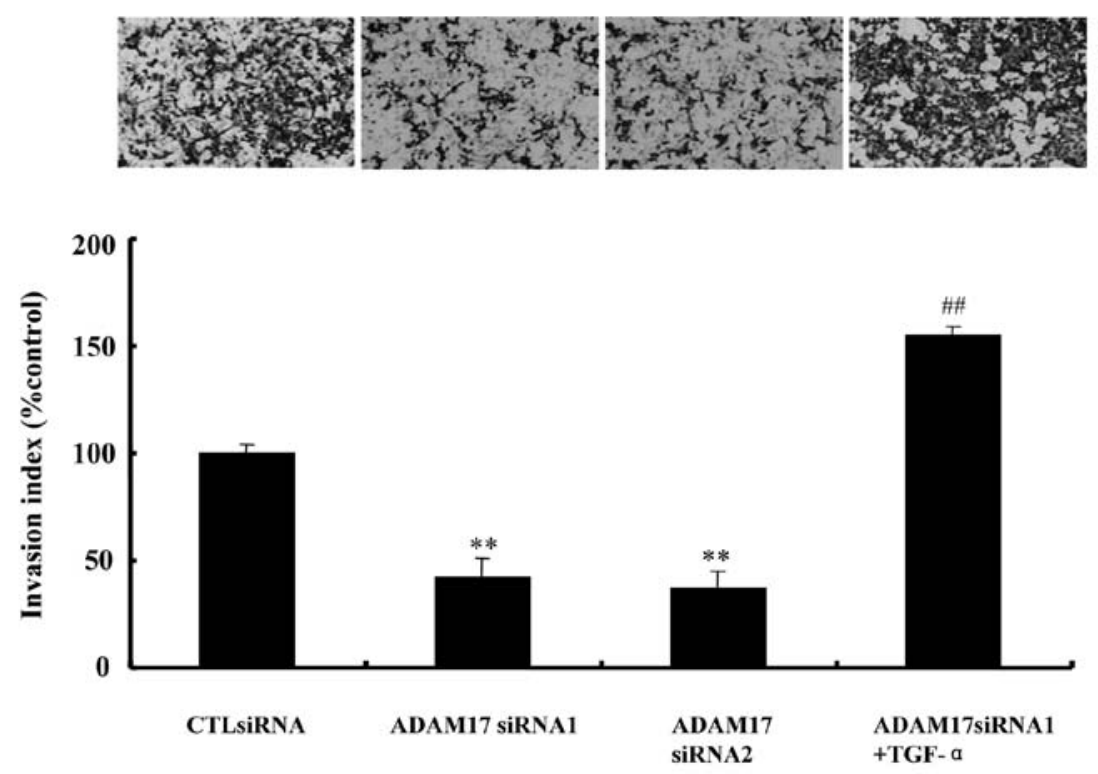

Figure 6. Continued. (E), Knockdown of ADAM17 decreased cell invasive ability, which could be reversed by simultaneous addition of TGF- $\alpha$. DU145 cells were transfected by ADAM17 siRNAs or CTL siRNA for $72 \mathrm{~h}$. Then cells were washed by PBS and typsinized, followed by cell counting. Cells $\left(1 \times 10^{5}\right)$ in $200 \mu 1$ serum-free media with or without $20 \mathrm{ng} / \mathrm{ml}$ soluble TGF- $\alpha$ were employed in Matrigel invasion assays as described in Materials and methods. ${ }^{* *}$ p $<0.01$ vs CTL siRNA. "\#p $<0.01$ vs ADAM17siRNA1.

results these studies suggest that ADAM17 promotes prostate cancer cells invasion by releasing soluble TGF- $\alpha$, which binds with EGFR and activates EGFR as well as its downstream signaling process ERK1/2, subsequently increasing MMP-2 and MMP-9 expression.

\section{Discussion}

Clinical observations provide evidence that despite current therapies, about one third of prostate cancers invade surrounding tissue, metastasize to distant organs, and consequently cause death. Survival of a patient with prostate cancer is directly related to the spread of the tumor (22). Therefore, an understanding of the mechanisms responsible for the regulation of invasion and metastasis is urgently needed in prostate cancer. ADAM17, acting as a signaling scissor in the tumor microenvironment has been associated with tumorigenesis and tumor progression (23). In breast cancer, ADAM17 was increased in high-grade versus low-grade invasive tumors (24), when ADAM17 was inhibited or suppressed there was attenuation in tumor invasiveness and malignancy, resulting in a better outcome for breast cancer patients (25). ADAM17 level has already been shown as an independent predictor of patient outcome (26). In renal cancer cells, silencing of ADAM17 was found to restore a dependence on exogenous growth factors, reduce invasion, and block in vivo tumor formation (27).

To investigate the functional role of ADAM17 in prostate cancer, we first examined its contribution to prostate cancer cell invasion. Five androgen-independent prostate cancer cell lines, which were derived from different metastatic sites and have different metastatic potential in vivo, were employed to clarify the correlation of ADAM17 expression level with cell invasive ability. The results showed ADAM17 was considerably increased in highly metastatic prostate cancer cell lines versus low metastatic and poorly metastatic cell lines. Stably overexpression of ADAM17 in PC-3 cells increased cell invasive ability, while knockdown of ADAM17 in DU145 cells decreased cell invasion, compared to untreated PC-3 cells or DU145 cells, respectively. Our results indicated that ADAM17 expression levels are correlated with the invasive ability in androgen-independent prostate cancer cell lines.

EGFR and its downstream signaling pathway are key regulators of tumor cell proliferation and metastasis in a variety of tumors (28). EGFR is frequently deregulated in cancers $(29,30)$. About $30 \%$ of PCa patients have EGFR overexpression (31). EGFR can be activated by one of seven possible ligands, each of which is initially expressed as a transmembrane precursor that is proteolytically shed from the cell surface by proteases (32). Extensive data show that ADAM17 is responsible for shedding of EGFR ligand, such as pro-TGF- $\alpha$, pro-HB-EGF, amphiregulin or epiregulin in different cells (12). Our study demonstrated that ADAM17 increased activation of EGFR as well as TGF- $\alpha$ release to the supernatant in PC-3-ADAM17 cells, compared to PC-3-Mock cells. A specific antibody to TGF- $\alpha$ blocked the activation of EGFR and decreased cell invasive ability of PC-3ADAM17 cells. Knockdown of ADAM17 inhibited EGFR activity, decreased TGF- $\alpha$ releasing and prevented DU145 cells to penetrate the extracellular matrix. However, this effect could be reversed by additional supplementation with recombinant soluble TGF- $\alpha(20 \mathrm{ng} / \mathrm{ml})$. TGF- $\alpha$ is one of the two EGFR ligands expressed in prostate cancer. Previous studies have demonstrated that with the disease progresses to more advanced stages, TGF- $\alpha$ is the predominant ligand for EGFR $(33,34)$. Moreover, cell lines derived from different prostatic cancers and their metastases, including DU145 overexpress TGF- $\alpha(35,36)$, and TGF- $\alpha$ /EGFR autocrine loop is a hallmark of PCa invasion and progression $(37,38)$. Therefore, based on these studies and our results, we concluded that ADAM17 contributes to PCa cell invasion through activation of EGFR pathway by shedding of pro-TGF- $\alpha$. TGF- $\alpha$ binding to EGFR 
leads to receptor self dimerization, autophosphorylation and subsequent activation of MEK-ERK and PI3K-Akt pathways, which are responsible for a variety of mitogenic, metastatic and other tumor-promoting cellular activity $(39,40)$.

In the present study we observed that ADAM17 activated ERK1/2 and Akt phosphorylation in PC-3-ADAM17 cells, compared to PC-3-Mock cells. In contrast, specific ablation of ADAM17 by siRNA decreased the activation of ERK1/2 and Akt, indicating that ADAM17 contributes to these signaling transduction pathways. Accordingly, suppression of EGFR or ERK1/2 activity by inhibitor AG1478 or PD98059, respectively, reduced the high invasion characteristics in PC-3-ADAM17 cells. These data further suggested that ADAM17 contributes to tumor invasion through activation of EGFR-MEK-ERK pathway.

However, we could not show the requirement of pAkt for invasion of PC-3-ADAM17 cells, because inhibition of PI3K-Akt pathway by inhibitor LY294002 had little influence on cell invasive ability. Consistent with our results, several studies have shown that $\mathrm{p}$-Akt was not required for invasion in androgen-dependent prostate cancer cell line MDA PCa $2 \mathrm{~b}$, as well as an androgen-refractory subline MDA-hr (22). A previous study also showed that prostate-restricted Akt hyperactivity caused prostatic intraepithelial neoplasia but not invasive cancer in the MPAKT (murine prostate restricted Akt kinase transgenic) mouse model (41). Accordingly, we found that PI3K-Akt pathway contributes to ADAM17-stimulated cell proliferation in PC-3 cells (unpublished data).

One of the key steps in cancer invasion and metastasis is the degradation of extracellular matrix. MMP-2 and MMP-9 have been demonstrated to play important roles in the process $(22,42)$. Many studies indicated that increased levels of MMP-2 or MMP-9 in the serum or tissue samples of prostate cancer patients are correlated with advanced stage $(43,44)$. In vitro studies also showed the expression of MMP-2 and MMP-9 associate with high invasive and metastatic potential of prostate cancer cell lines (45-48). Moreover, the expression of MMP-2, MMP-9 or TIMP-3 showed a 100\% specificity for diagnoses of prostate cancer (49). These results suggested that up-regulated expression of MMP-2 and MMP-9 may be critical to PCa progression. Our results showed MMP-2 and MMP-9 expression levels were increased by high ADAM17 expression, and decreased by lower ADAM17 expression in PC-3-ADAM17 cells and DU145-ADAM17-siRNA transfected cells, compared to control, respectively. Moreover, specific ablation of MMP-2 or MMP-9 by siRNAs inhibited cell invasion of PC-3-ADAM17 cells, further demonstrating the importance of MMP-2 and MMP-9 in ADAM17-mediated prostate cancer cell invasion.

Although it has been indicated that MMP expression is regulated by EGFR and downstream signal pathway, whether expression of MMP-2 and MMP-9 is regulated by PI3K-Akt or MEK-ERK pathway is controversial in prostate cancer. Preincubation of PC-3-ADAM17 cells with EGFR or ERK inhibitor AG1478 or PD98059 attenuated MMP-2 and MMP-9 expression significantly, while no similar result was observed with PI3K-Akt inhibitor LY294002. Consistently, knockdown of ADAM17 by siRNA caused substantial down-regulation of MMP-2 and MMP-9, which were reversed by simultaneous addition of TGF- $\alpha$ and subsequent reactivation of EGFR and ERK.
Taken together, these results suggest that ADAM17 prompted prostate cancer cell invasion by up-regulating expression of MMP-2 and MMP-9 through activation of EGFR-MEK-ERK signal pathway.

In conclusion, we have demonstrated for the first time that ADAM17 contributes to androgen-independent prostate cancer cell invasion by shedding EGFR ligand TGF- $\alpha$, which subsequently activates the EGFR-MEK-ERK signaling pathway, leading finally to expression of MMP-2 and MMP-9. These data indicate that ADAM17 facilitates prostate cancer cell metastases to other organs. Taken together, the present study suggests that ADAM17 expression level may be a new predictive biomarker of invasion and metastasis of prostate cancer. ADAM17 could provide a target for treating metastatic PCa, and as such, the development of ADAM17 inhibitors or specific methods for overexpressed ADAM17 in tumor treatment warrants further study.

\section{Acknowledgements}

This work was supported by grants from the National Natural Science Foundation of China (no. 30772173), the Natural Science Foundation of Heilongjiang Province, P.R. China (no. D2007-56), and the Innovation Fund Project for Graduate student of Heilongjiang Province, P.R. China (no. YJSCX2009218HLJ).

\section{References}

1. Society AC: Cancer facts and figures, 2009. Atlanta, American Society, 2009.

2. McCulloch DR, Harvey M and Herington AC: The expression of the ADAMs proteases in prostate cancer cell lines and their regulation by dihydrotestosterone. Mol Cell Endocrinol 167: 11-21, 2000.

3. Saleem M, Adhami VM, Zhong W, et al: A novel biomarker for staging human prostate adenocarcinoma: overexpression of matriptase with concomitant loss of its inhibitor, hepatocyte grow th factor activator inhibitor-1. Cancer Epidemiol Biomarkers Prev 15: 217-227, 2006.

4. Saleem M, Kweon MH, Johnson JJ, et al: S100A4 accelerates tumorigenesis and invasion of human prostate cancer through the transcriptional regulation of matrix metalloproteinase 9. Proc Natl Acad Sci USA 103: 14825-14830, 2006.

5. Blobel CP: ADAMs: key components in EGFR signalling and development. Nat Rev Mol Cell Biol 6: 32-43, 2005.

6. Edwards DR, Handsley MM and Pennington CJ: The ADAM metalloproteinases. Mol Aspects Med 29: 258-289, 2008.

7. Lu X, Lu D, Scully M and Kakkar V: ADAM proteins - therapeutic potential in cancer. Curr Cancer Drug Targets 8: 720-732, 2008.

8. Arribas $\mathrm{J}$ and Esselens C: ADAM17 as a therapeutic target in multiple diseases. Curr Pharm Des 15: 2319-2335, 2009.

9. Nath D, Slocombe PM, Stephens PE, et al: Interaction of metargidin (ADAM-15) with alphavbeta3 and alpha5beta1 integrins on different haemopoietic cells. J Cell Sci 112: 579-587, 1999.

10. Black RA, Rauch CT, Kozlosky CJ, et al: A metalloproteinase disintegrin that releases tumour-necrosis factor-alpha from cells. Nature 385: 729-733, 1997.

11. Moss ML, Jin SL, Milla ME, et al: Cloning of a disintegrin metalloproteinase that processes precursor tumour-necrosis factor-alpha. Nature 385: 733-736, 1997.

12. Sahin U, Weskamp G, Kelly K, et al: Distinct roles for ADAM10 and ADAM17 in ectodomain shedding of six EGFR ligands. $J$ Cell Biol 164: 769-779, 2004.

13. Tsakadze NL, Sithu SD, Sen U, English WR, Murphy G and D'Souza SE: Tumor necrosis factor-alpha-converting enzyme (TACE/ADAM-17) mediates the ectodomain cleavage of intercellular adhesion molecule-1 (ICAM-1). J Biol Chem 281: 3157-3164, 2006. 
14. Garton KJ, Gough PJ, Philalay J, et al: Stimulated shedding of vascular cell adhesion molecule 1 (VCAM-1) is mediated by tumor necrosis factor-alpha-converting enzyme (ADAM 17). J Biol Chem 278: 37459-37464, 2003.

15. Garton KJ, Gough PJ, Blobel CP, et al: Tumor necrosis factoralpha-converting enzyme (ADAM17) mediates the cleavage and shedding of fractalkine (CX3CL1). J Biol Chem 276: 37993-38001, 2001.

16. Schramme A, Abdel-Bakky MS, Kampfer-Kolb N, Pfeilschifter J and Gutwein P: The role of CXCL16 and its processing metalloproteinases ADAM10 and ADAM17 in the proliferation and migration of human mesangial cells. Biochem Biophys Res Commun 370: 311-316, 2008

17. Planque C, Kulasingam V, Smith CR, Reckamp K, Goodglick L and Diamandis EP: Identification of five candidate lung cancer biomarkers by proteomics analysis of conditioned media of four lung cancer cell lines. Mol Cell Proteomics 8: 2746-2758, 2009.

18. Oh ST, Schramme A, Stark A, Tilgen W, Gutwein P and Reichrath J: The disintegrin-metalloproteinases ADAM 10,12 and 17 are upregulated in invading peripheral tumor cells of basal cell carcinomas. J Cutan Pathol 36: 395-401, 2009.

19. Kornfeld JW, Meder S, Wohlberg M, et al: Overexpression of TACE and TIMP3 mRNA in head and neck cancer: association with tumour development and progression. Br J Cancer 104: 138-145, 2011.

20. Karan D, Lin FC, Bryan M, et al: Expression of ADAMs (a disintegrin and metalloproteases) and TIMP-3 (tissue inhibitor of metalloproteinase-3) in human prostatic adenocarcinomas. Int J Oncol 23: 1365-1371, 2003.

21. Zheng $\mathrm{X}$, Jiang $\mathrm{F}$, Katakowski M, Zhang ZG, Lu QE and Chopp M: ADAM17 promotes breast cancer cell malignant phenotype through EGFR-PI3K-AKT activation. Cancer Biol Ther 8: 1045-1054, 2009.

22. Hara T, Miyazaki H, Lee A, Tran CP and Reiter RE: Androgen receptor and invasion in prostate cancer. Cancer Res 68: 1128-1135, 2008.

23. Murphy G: The ADAMs: signalling scissors in the tumour microenvironment. Nat Rev Cancer 8: 929-941, 2008.

24. McGowan PM, Ryan BM, Hill AD, McDermott E, O'Higgins N and Duffy MJ: ADAM-17 expression in breast cancer correlates with variables of tumor progression. Clin Cancer Res 13 2335-2343, 2007.

25. Glunde K and Stasinopoulos I: ADAM17: the new face of breast cancer-promoting metalloprotease activity. Cancer Biol Ther 8 : $1055-1057,2009$

26. McGowan PM, McKiernan E, Bolster F, et al: ADAM-17 predicts adverse outcome in patients with breast cancer. Ann Oncol 19 1075-1081, 2008

27. Franovic A, Robert I, Smith K, et al: Multiple acquired renal carcinoma tumor capabilities abolished upon silencing of ADAM17. Cancer Res 66: 8083-8090, 2006.

28. Gusterson BA: Identification and interpretation of epidermal growth factor and c-erbB-2 overexpression. Eur J Cancer 28 : 263-267, 1992

29. Kenny PA: Three-dimensional extracellular matrix culture models of EGFR signalling and drug response. Biochem Soc Trans 35: 665-668, 2007.

30. Kenny PA: TACE: a new target in epidermal growth factor receptor dependent tumors. Differentiation 75: 800-808, 2007.

31. Shah RB, Ghosh D and Elder JT: Epidermal growth factor receptor (ErbB1) expression in prostate cancer progression: correlation with androgen independence. Prostate 66: 1437-1444, 2006.
32. Harris RC, Chung E and Coffey RJ: EGF receptor ligands. Exp Cell Res 284: 2-13, 2003.

33. Seth D, Shaw K, Jazayeri J and Leedman PJ: Complex posttranscriptional regulation of EGF-receptor expression by EGF and TGF-alpha in human prostate cancer cells. Br J Cancer 80: 657-669, 1999.

34. De Haan AM, Wolters NM, Keller ET and Ignatoski KM: EGFR ligand switch in late stage prostate cancer contributes to changes in cell signaling and bone remodeling. Prostate 69: 528-537, 2009.

35. Ching KZ, Ramsey E, Pettigrew N, D'Cunha R, Jason M and Dodd JG: Expression of mRNA for epidermal growth factor, transforming growth factor-alpha and their receptor in human prostate tissue and cell lines. Mol Cell Biochem 126: 151-158, 1993.

36. Morris GL and Dodd JG: Epidermal growth factor receptor mRNA levels in human prostatic tumors and cell lines. J Urol 143: 1272-1274, 1990.

37. Formento P, Hannoun-Levi JM, Gerard F, et al: Gefitinibtrastuzumab combination on hormone-refractory prostate cancer xenograft. Eur J Cancer 41: 1467-1473, 2005.

38. Mimeault M, Venkatraman G, Johansson SL, et al: Novel combination therapy against metastatic and androgen-independent prostate cancer by using gefitinib, tamoxifen and etoposide. Int J Cancer 120: 160-169, 2007.

39. Wells A: EGF receptor. Int J Biochem Cell Biol 31: 637-643, 1999.

40. Grant S, Qiao L and Dent P: Roles of ERBB family receptor tyrosine kinases, and downstream signaling pathways, in the control of cell growth and survival. Front Biosci 7: d376-d389, 2002.

41. Majumder PK, Yeh JJ, George DJ, et al: Prostate intraepithelial neoplasia induced by prostate restricted Akt activation: the MPAKT model. Proc Natl Acad Sci USA 100: 7841-7846, 2003.

42. Libra M, Scalisi A, Vella N, et al: Uterine cervical carcinoma: role of matrix metalloproteinases (Review). Int J Oncol 34: 897-903, 2009.

43. Roy R, Louis G, Loughlin KR, et al: Tumor-specific urinary matrix metalloproteinase fingerprinting: identification of high molecular weight urinary matrix metalloproteinase species. Clin Cancer Res 14: 6610-6617, 2008.

44. Wang Q, Diao X, Sun J and Chen Z: Regulation of VEGF, MMP-9 and metastasis by CXCR4 in a prostate cancer cell line. Cell Biol Int 35: 897-904, 2011.

45. Flaig TW, Gustafson DL, Su LJ, et al: A phase I and pharmacokinetic study of silybin-phytosome in prostate cancer patients. Invest New Drugs 25: 139-146, 2007.

46. Nabeshima K, Inoue T, Shimao Y and Sameshima T: Matrix metalloproteinases in tumor invasion: role for cell migration. Pathol Int 52: 255-264, 2002.

47. Hwang MK, Song NR, Kang NJ, Lee KW and Lee HJ: Activation of phosphatidylinositol 3-kinase is required for tumor necrosis factor-alpha-induced upregulation of matrix metalloproteinase-9: its direct inhibition by quercetin. Int J Biochem Cell Biol 41: 1592-1600, 2009

48. Aalinkeel R, Nair BB, Reynolds JL, et al: Overexpression of MMP-9 contributes to invasiveness of prostate cancer cell line LNCaP. Immunol Invest 40: 447-464, 2011.

49. Escaff S, Fernandez JM, Gonzalez LO, et al: Comparative study of stromal metalloproteases expression in patients with benign hyperplasia and prostate cancer. J Cancer Res Clin Oncol 137: 551-555, 2011. 